\title{
COVID-19, parvovirus and acute HIV infection in the gamut of diagnosis of fever and rash
}

\author{
Oguz Abdullah UYAROGLU ${ }^{1}$ (D), Lale OZISIK ${ }^{1}$ (D), Nursel CALIK BASARAN ${ }^{1}$ (D), Gulcin TELLI DIZMAN² (D), Zahit TAS ${ }^{2}$ (D), \\ Murat OZDEDE $^{1}$ (D), Ahmet Cagkan INKAYA ${ }^{2}$ (D), Gulay SAIN GUVEN ${ }^{1}$ \\ ${ }^{1}$ Division of General Internal Medicine, Department of Internal Medicine, Faculty of Medicine, Hacettepe University, Ankara, Turkey. \\ ${ }^{2}$ Department of Infectious Diseases and Clinical Microbiology, Faculty of Medicine, Hacettepe University, Ankara, Turkey.
}

Corresponding Author: Oguz Abdullah UYAROGLU

E-mail: oguzuyaroglu@hotmail.com

Submitted: $16.06 .2021 \quad$ Accepted: 13.09.2021

\begin{abstract}
Coronavirus disease-19 (COVID-19) patients continue to experience different symptoms each day. Many patients were seen with common symptoms such as fever, fatigue, myalgia, respiratory symptoms (e.g., dry cough, dyspnea), smell and taste disorders, gastrointestinal symptoms, and dermatological findings. Although, fever lasting $<7$ days has been reported in most patients, it has been seen in patients with persistent or recurrent fever patterns in the second week of illness.

Although, any symptoms accompanying fever during the pandemic suggest the diagnosis of COVID-19, other etiologies should also be kept in mind. In this case report, we present two patients who were admitted with fever and rash were initially thought to have COVID-19 but were diagnosed with acute parvovirus infection and acute HIV infection finally.

These cases are presented to draw attention to the importance of taking a good history and making a rational differential diagnosis.

Keywords: COVID-19, Parvovirus, HIV, Fever, Rash, Cutaneous manifestations
\end{abstract}

\section{INTRODUCTION}

The coronavirus disease-2019 (COVID-19) caused by severe acute respiratory syndrome coronavirus-2 (SARSCoV-2) spread rapidly all over the world and was declared as 'pandemic' by the World Health Organization (WHO) on March $11^{\text {th }}, 2020$ [1]. With the increase of patients worldwide, the clinical spectrum of COVID-19 is being better defined and new symptoms are noticed. Most studies in hospitalized patients reveal that the common symptoms of COVID-19 are respiratory (eg dry cough, dyspnea) with fever, fatigue, myalgia $[2,3]$, but smell and taste disorders, gastrointestinal symptoms, and dermatologic findings have also been reported [4-6].

In the midst of pandemic, clinicians should suspect COVID-19 in every case of prolonged fever but also do not forget other etiologies. Although, fever was reported in about 72-98.6\% of patients, usually lasting $<7$ days, there were patients who had fever persisting into the second week of illness or had a saddleback pattern of fever [7].

As the data related to COVID-19 emerged, it was observed that patients might manifest with dermatological findings such as; contact dermatitis-like itch, urticarial lesions, chicken-pox lesions, exacerbation of pre-existing skin diseases, including seborrheic dermatitis and acne, and vasculitic skin lesions [8].

Along with the current literature, COVID-19 emerged as a disease that should be included in the differential diagnosis of fever and rash. Here, we report two cases presented with fever and rash, mimicking COVID-19 with clinical and laboratory findings, diagnosed as acute parvovirus infection and acute human immunodeficiency virus-1 (HIV)-1 infection, respectively.

How to cite this article: Uyaroglu OA, Ozisik L, Calik Basaran N, et al. COVID-19, parvovirus and acute HIV infection in the gamut of diagnosis of fever and rash. Marmara Med J 2022: 35(1):115-120. doi: 10.5472/marumj.1065886 


\section{CASE REPORTS}

\section{Case 1}

A 38-year-old male anesthesiologist applied to outpatient clinics of infectious diseases with a two-day history of fever $\left(38.7^{\circ} \mathrm{C}\right)$, fatigue, myalgia, and arthralgia on 20 March 2020. He reported dry cough without dyspnea and other respiratory complaints. He denied any history of travel and contact with a recent traveler or confirmed COVID-19 patient. On presentation, he looked clinically well and his body temperature was $37.4^{\circ} \mathrm{C}$ with normal blood pressure and heart rate. Physical examination was unremarkable except for decreased lung sounds at the left lower posterior chest. Chest radiography was normal. Laboratory tests revealed lymphopenia and mild thrombocytopenia. As it was influenza season, oseltamivir was commenced.

Table I. Laboratory findings of the patients

\begin{tabular}{|c|c|c|c|}
\hline Measure & Reference Range & Case 1 & Case 2 \\
\hline Hemoglobin (g/dL) & $11.7-15.5$ & 13.7 & 11.8 \\
\hline White-cell count $(\mu \mathrm{L})$ & $4100-10200$ & 3100 & 4400 \\
\hline Absolute neutrophil count $(\mu \mathrm{L})$ & $1800-6400$ & 2240 & 3220 \\
\hline Absolute lymphocyte count $(\mu \mathrm{L})$ & $1200-3600$ & 520 & 850 \\
\hline Platelet count $(\mu \mathrm{L})$ & $159000-388000$ & 138.000 & 212.000 \\
\hline Creatinine (mg/dL) & $0.67-1.17$ & 0.89 & 0.62 \\
\hline Blood Urea Nitrogen $(\mathrm{mg} / \mathrm{dL})$ & $6-20$ & 11.1 & 7.98 \\
\hline Alanine aminotransferase $(\mathrm{U} / \mathrm{L})$ & $<50$ & 34 & 410 \\
\hline $\begin{array}{l}\text { Aspartate aminotransferase } \\
(\mathrm{U} / \mathrm{L})\end{array}$ & $<50$ & 37 & 695 \\
\hline Gamaglutamil transferase $(\mathrm{U} / \mathrm{L})$ & $<38$ & 44 & 334 \\
\hline Alkalen phospatase (U/L) & $30-120$ & 39 & 131 \\
\hline Total Bilirubin (mg/dL) & $0.3-1.2$ & 1.33 & 0.90 \\
\hline Creatin Kinase (U/L) & $<145$ & 62 & 2935 \\
\hline Lactate Dehidrogenase (U/L) & $<247$ & 178 & 2951 \\
\hline D-dimer $(\mathrm{mg} / \mathrm{L})$ & $0-0.55$ & 1.35 & 8.07 \\
\hline C-reactive Protein $(\mathrm{mg} / \mathrm{dL})$ & $0-0.8$ & 6.66 & 2.84 \\
\hline Procalcitonin $(\mathrm{ng} / \mathrm{mL})$ & $0-0.1$ & 0.27 & 1.261 \\
\hline Sedimantation (mm/saat) & $0-20$ & 5 & 17 \\
\hline Ferritin $(\mu \mathrm{g} / \mathrm{L})$ & $11-307$ & 185 & 6561 \\
\hline
\end{tabular}

He did not defervesce under oseltamivir treatment, and he developed arthralgia at the small joints of the hands, wrists, elbows, eventually he was re-admitted for further evaluation on the 8th day of fever. He had no dyspnea and hypoxia. His body temperature was $38.4^{\circ} \mathrm{C}$. Bilateral, non-pruritic, maculopapular rash was present in the lower limbs (Figure 1). There was no "slapped cheek" sign or any other facial lesions specific to parvovirus infection. He had mild tenderness with no heat or swelling at his proximal interphalangeal (PIP) and distal interphalangeal (DIP) joints. He was capable of closing his fist totally with a normal hand grip. Laboratory tests revealed lymphopenia and mild thrombocytopenia. There was no red cell aplasia. C-reactive protein (CRP) and D-dimer levels were significantly elevated (Table 1). He was hospitalized and isolated with standard, contact, and droplet precautions as a probable COVID-19 case. Repeated SARS-CoV-2 real-time polymerase chain reaction (PCR) test results with nasopharyngeal swab were negative. A control chest computed tomography (CT) turned out normal. Transthoracic echocardiography ruled out endocarditis. An abdomen ultrasound confirmed splenomegaly of $15.5 \mathrm{~cm}$.

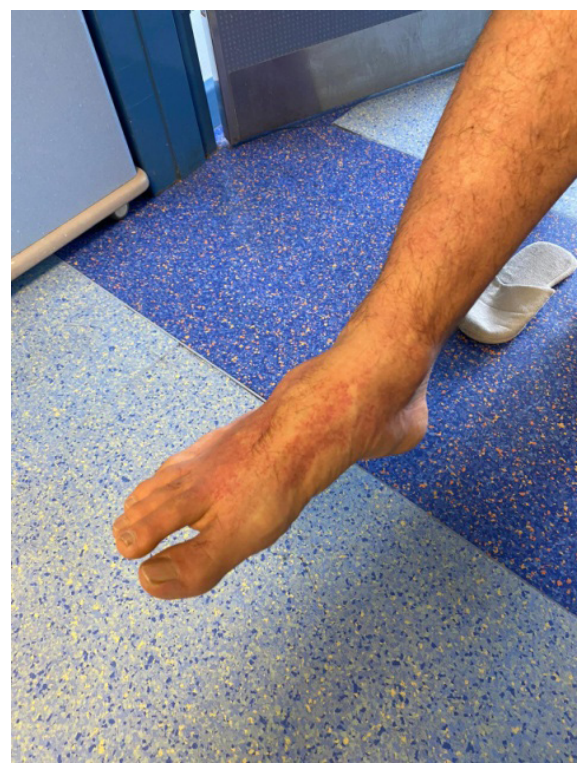

Figure 1. Non-pruritic maculopapular rash on the dorsum of right foot

Antinuclear anti-body (ANA) was positive at a titer of $1 / 160$ with granular and nucleolar pattern. Double-stranded DNA (dsDNA) and extractable nuclear antigen (ENA) antibodies [ anti-ribonucleoprotein (Anti-RNP), anti-Sjögren syndrome A-B (anti-SSA, SSB), scleroderma antibodies (Scl-70 and anti-Jo-1) were negative. Rheumatoid factor (RF) was 38.8 $\mathrm{IU} / \mathrm{mL}(0-20 \mathrm{IU} / \mathrm{mL})$, anti-cyclic citrullinated peptide (anti$\mathrm{CCP}$ ) and complement levels were within the normal ranges. Diagnostic criteria of any rheumatological disease was not met and rheumatology consultation ruled out probable connective tissue disorder.

Blood and urine cultures remained sterile. Extensive viral and bacterial screening, ruled out Epstein-Barr virus, cytomegalovirus, rubella, hepatitis A,B,C (HAV, HBV, HVC), human immunodeficiency virus (HIV), Coxiella spp., and Brucella spp. infections.

A skin biopsy of the maculopapular rash was performed and reported as non-specific.

As the patient suffered from fever, malaise, arthralgia, maculopapular rash and had splenomegaly, lymphopenia and 
elevated CRP, parvovirus infection was considered. Parvovirus PCR from peripheral blood was positive at $55200 \mathrm{IU} / \mathrm{ml}$ and the patient diagnosed with parvovirus infection. Acetaminophen was ordered to alleviate symptoms. He became symptom-free after day 10.

\section{Case 2}

A 27-year-old female presented with a 10-day history of fever, dry cough, and sore throat, and rash. She was previously seen by a family physician who commenced oral amoxicillin treatment for exudative pharyngitis. On admission, her body temperature was $38.5^{\circ} \mathrm{C}$, blood pressure was $90 / 50 \mathrm{~mm} \mathrm{Hg}$, her pulse was 112 beats per minute, respiratory rate was 18/ minute, and oxygen saturation was $98 \%$ in room air. She had hyperemic oropharynx and enlarged cervical and axillary lymph nodes. Erythematous macular patches were present all over her body (Figure 2). She was hospitalized and isolated as a probable COVID-19 case.

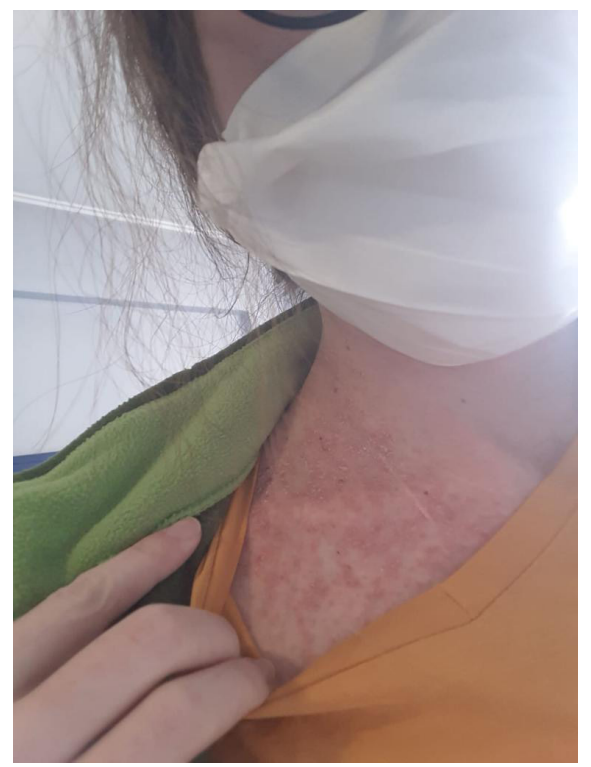

Figure 2. Erythematous macular patches on the front of the neck

Multiplex respiratory PCR panel and SARS-CoV-2 reverse transcriptase-PCR from nasopharyngeal swap turned out negative. Chest CT scan demonstrated normal lung parenchyma, minimal left-sided pleural effusion, and bilateral, slightly thickened axillary lymph nodes with short diameters less then $1 \mathrm{~cm}$. Dermatology consultation was done for confluent erythematous macular patches fading under pressure all over her body and the patient was put on topical clobetasol 17-propionate with the suspicion of drug eruption or infectious mononucleosis.

The levels of erythrocyte sedimentation rate (ESR), CRP, procalcitonin, D-dimer, ferritin, aspartate aminotransferase (AST), alanine aminotransferase (ALT), gamma-glutamyl transferase (GGT), and $\mathrm{LDH}$, creatine kinase (CK) were elevated. Serological analysis indicated no infection with Borrelia burgdorferi, parvovirus, rubella, HAV, $\mathrm{HBV}, \mathrm{HCV}$, Epstein-Barr virus, and cytomegalovirus and coxiella burnetii. Anti-streptolysin titer (ASO) and RF, ANA, anti-neutrophil cytoplasmic antibodies (ANCA) were negative. Cultures of blood and urine were negative (Table I).

Although, we could not demonstrate SARS-CoV-2 infection, oral hydroxychloroquine and azithromycin were started as endorsed by national guidelines [9]. The patient did not defervesce and her general condition remained unchanged, and for this reason favipiravir was added to the treatment regimen, and the patient was further evaluated as the fever-of-unknown origin. Cervical CT revealed bilateral multiple heterogeneous enlarged lymph nodes in cervical level 2. Abdominal CT demonstrated increased contrast-enhancement in the gallbladder wall with diffusely edematous gallbladder bed. A wedge-shaped hypodense region was observed at the level of the falciform ligament that was compatible with focal steatosis increased size and density in the left ovary, increased density of the anterior uterus, and minimal free fluid was detected at the pelvis and at the right paracolic groove. These findings were consistent with pelvic inflammatory disease (PID) and Fitz Hugh Curtis Syndrome (FHC) (Figure 3). Multiplex real - time PCR from endocervical sample turned out positive for Mycoplasma genitalium. Gentamycin, ceftriaxone and doxycycline treatments were started. Sexually transmitted disease (STD) screening was performed and ruled out syphilis, gonorrhea, chlamiydia, and herpes virus infections. Fourthgeneration HIV enzyme-linked immunoassay (ELISA) test was positive and HIV confirmatory test revealed positive for p24 antigen but negative for anti - HIV antibodies. HIV viral load was above the detection limit (>10000000 copies/ml). Eventually, Fiebig stage II primary HIV infection was diagnosed. As soon as the patient was informed about the diagnosis, antiretroviral regimen, composed of $200 \mathrm{mg}$ emtricitabine / $245 \mathrm{mg}$ tenofovir disoproxil fumarate and $50 \mathrm{mg}$ dolutegravir was commenced. Liver function tests started to improve with the treatment of PID and antiretroviral treatment. The patient was discharged 2 days later and is being under follow-up at the outpatient clinic of infectious diseases department. 


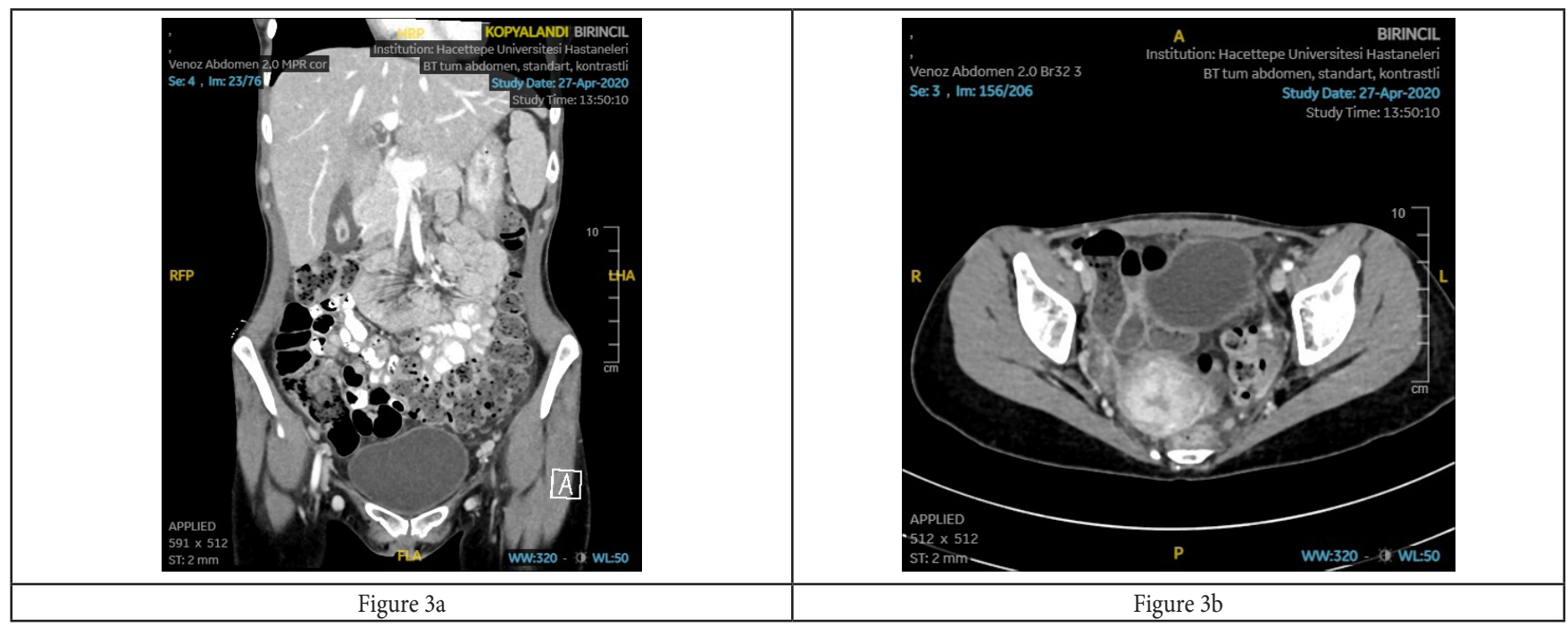

Figure 3. Abdominopelvic computerized tomography images of case 2

3a. Increased contrast-enhancement of the gallbladder wall with diffusely edematous gallbladder bed

3b. A wedge-shaped hypodense region was observed at the level of the falsiform ligament which was compatible with focal steatosis increased size and density in the left ovary, increased density of the anterior uterus, and minimal free fluid was detected at the pelvis and at the right paracolic groove. These findings were consistent with pelvic inflammatory disease (PID) and Fitz Hugh Curtis Syndrome (FHC)

\section{DISCUSSION}

Here we report 2 cases who presented with COVID-19 symptoms of rash and fever, mimicking COVID-19 with clinical and laboratory features, were diagnosed parvovirus and acute HIV infection, respectively.

Diagnosing patients with fever and rash is a challenge for physicians. They need a fast and rational approach because some of these patients may be in a life-threatening situation or need isolation to reduce their potential transmission risk to others. For clinical diagnosis a complete history and a careful physical examination are essential. Epidemiologic clues are also important such as age, travel/sexual history, season, geographic location, exposures including to insects, animals and ill contacts, medications, immunizations, and history of childhood illnesses [10].

In a prospective study about clinical features and etiology of adult patients with fever and rash, the etiology were divided into three groups as infectious (50\%), noninfectious (40\%), and undiagnosed (10\%). The most common type of rash is maculopapular, and the most common 5 causes are measles, cutaneous drug reactions, varicella, adult-onset Still's disease, and rickettsial disease [11].

Rashes are generally non-specific but have complementary importance in the differential diagnosis when other symptoms are combined with the characteristics of the rash, such as the history of medication and allergies or the social and environmental background, as well as morphology, location, and distribution [12]. In addition to basic laboratory tests, dermatology consultation and skin biopsy may be required to diagnose.
Presented patients had both fever and rash. Parvovirus and HIV are also in the differential diagnosis of fever and rash syndromes. Approximately $25 \%$ of parvovirus infected individuals will present with rash and/or arthralgias. There was joint tenderness in the proximal interphalangeal (PIP) and distal interphalangeal (DIP) joints of case 1. Joint symptoms with parvovirus are usually acute, symmetric, and most frequently involve the small joints of the hands, wrists and knees [13]. There are case reports of acute parvovirus infection-causing transient autoimmune state manifesting as the presence of autoantibodies [14]. ANA were also reactive in case 1 . In the absence of a sound exposure history, we were misled toward diagnosing a connective tissue disorder. In parvovirus infection rash most commonly occurs in children, when it occurs in adults, the rash is often less characteristic.

A morbilliform rash predominantly involving the trunk has been reported as the most common cutaneous manifestation of COVID-19 [15]. Since, the patient had fever, arthralgia, rash, lymphopenia and high D-dimer we had to rule out COVID-19. Lymphopenia and/or thrombocytopenia can also be observed in parvovirus infection [16]. Since, these laboratory results are not specific, all possible infections should be kept in mind in the differential diagnosis.

The case 2 had fever, dry cough and there was maculopapular rash on physical examination. Fever is present in the vast majority of patients with symptomatic primary HIV infection. A generalized rash is also a common finding. Apart from these complaints, dry cough and sore throat also can be seen in primary HIV infection [17]. Needless to say, none of these findings is specific and COVID-19 may well have just presented with similar symptoms. Because of the wide range of symptoms 
associated with primary HIV infection, clinicians could have a low level of suspicion.

In current pandemic days, COVID-19 ranks the first in the differential diagnosis of all patients with fever plus any other symptom. Focusing only on the diagnosis of COVID-19 may cause us to skip many other diagnoses. In a proportion meta-analysis, fever (84.8\%; 95\% CI, $78.5 \%$ to $90.1 \%$ ) was identified as the most common clinical manifestation in all COVID-19 patients [18]. Multiple skin manifestations such as exanthematous rash, pernio (chilblain)-like acral lesions, livedolike/retiform purpura/necrotic vascular lesions, urticaria, vesicular (varicella-like) eruptions have also been described in patients with confirmed or suspected COVID-19 [19,20].

To establish the etiology of febrile illness and rash of our patients we carefully performed the evaluations, keeping in mind that fever cannot only be caused by COVID-19 but also by other common causes that are consistent through the decades, even during the pandemic.

In conclusion, in the midst of pandemic, clinicians should suspect COVID-19 in every case of prolonged fever but also do not forget other etiologies. Obtaining an accurate history and making a rational differential diagnostic work-up is more important than ever. Last but not least, COVID-19, is new and attractive, but we cannot ignore the old "ones". Keep oldies in mind.

Patient Consent: Both patients gave their consent for images and other clinical information relating to their cases to be reported in a medical publication.

Conflict of interest: The authors have no conflicts of interest to declare.

Funding: No financial support was received for this study. The authors have no financial or proprietary interest in any material or method mentioned.

Author Contributions: OAU: Coordinated and supervised data collection, reviewed and revised the manuscript, drafted the initial manuscript and wrote the final manuscript. LO, NCB, TS, GTD, MO and ACI: Had active roles in the diagnosis and treatment of the patients. GSG, ACI: Conceptualized and designed the case, coordinated and supervised data collection. All authors read and approved the final version of the article.

\section{REFERENCES}

[1] Yang X, Yu Y, Xu J, et al. Clinical course and outcomes of critically ill patients with SARS-CoV-2 pneumonia in Wuhan, China: a single-centered, retrospective, observational study. Lancet Respir Med 2020;8:475-81. doi: 10.1016/S22132600(20)30079-5.

[2] Wang D, Hu B, Hu C, et al. Clinical characteristics of 138 hospitalized patients with 2019 novel coronavirus-infected pneumonia in Wuhan, China. JAMA 2020;323:1061-9. doi: 10.1001/jama.2020.1585.

[3] Zheng F, Tang W, Li H, Huang YX, Xie YL, Zhou ZG. Clinical characteristics of 161 cases of corona virus disease 2019
(COVID-19) in Changsha. Eur Rev Med Pharmacol Sci 2020;24:3404-10. doi: 10.26355/eurrev_202003_20711.

[4] Lechien JR, Chiesa-Estomba CM, Hans S, Barillari MR, Jouffe L, Saussez S. Loss of smell and taste in 2013 European patients with mild to moderate COVID-19 [published online ahead of print, 2020 May 26]. Ann Intern Med 2020;10.7326/M202428. doi:10.7326/M20-2428

[5] Nobel YR, Phipps M, Zucker J, et al. Gastrointestinal symptoms and coronavirus disease 2019: A case-control study from the United States. Gastroenterology 2020;159:373-5.e2. doi: 10.1053/j.gastro.2020.04.017.

[6] Sachdeva M, Gianotti R, Shah $M$, et al. Cutaneous manifestations of COVID-19: Report of three cases and a review of literature. J Dermatol Sci 2020;98:75-81. doi: 10.1016/j.jdermsci.2020.04.011.

[7] Deborah H L Ng, Chiaw Yee Choy, Yi-Hao Chan, et al. National Centre for Infectious Diseases COVID-19 Outbreak Research Team, fever patterns, cytokine profiles, and outcomes in COVID-19. Open Forum Infect Dis Volume 2020;9:ofaa375. doi: 10.1093/ofid/ofaa375

[8] Marzano AV, Cassano N, Genovese G, Moltrasio C, Vena GA. Cutaneous manifestations in patients with COVID-19: a preliminary review of an emerging issue. Br J Dermatol 2020 ;10:1111/bjd.19264. doi: 10.1111/bjd.19264.

[9] Republic of Turkey Ministry of Health Directorate 2020. COVID-19 (SARS-CoV-2 Infection) Guide (in Turkish). Available at: https://covid19bilgi.saglik.gov.tr/depo/rehberler/ COVID-19_Rehberi.pdf. Accessed on: 14.04. 2020.

[10] Kang JH. Febrile Illness with skin rashes. Infect Chemother 2015;47:155-66. doi: 10.3947/ic.2015.47.3.155.

[11] Tabak F, Murtezaoglu A, Tabak O, et al. Clinical features and etiology of adult patients with fever and rash. Ann Dermatol 2012;24:420-5. doi: 10.5021/ad.2012.24.4.420.

[12] Saffar MJ, Saffar H, Shahmohammadi S. Fever and rash syndrome: A review of clinical practice guidelines in the differential diagnosis. J Pediatr Rev 1.2 2013: 42-54. Available at: http://jpr.mazums.ac.ir/article-1-57-en.html Accessed on: 17.04.2020

[13] Alexander V, Das S, Mangan AS, Iyadurai R. Acute parvovirus B19 infection presenting as rheumatoid arthritis mimic. J Family Med Prim Care 2019;8:1257-9. doi: 10.4103/jfmpc. jfmpc_25_19.

[14] Cooray Mi Manolakos JJ, Douglas SW, Haider S, Patel A. Parvovirus infection mimicking systemic lupus erythematosus. Case Reports. CMAJ 2013; 185: 1342-4. doi: 10.1503/cmaj.121565

[15] Woolina U, Karadag AS, Rowland-Payne C, Cihrac A, Lotti T. Cutaneous signs in COVID-19 patients: A review. Derm Ther 2020;e13549 doi:10.1111/dth.13549.

[16] Waza K, Inoue K, Matsumura S. Symptoms associated with parvovirus B19 infection in adults: a pilot study. Intern Med 2007; 46:1975. doi: 10.2169/internalmedicine.46.0366

[17] Robb ML, Eller LA, Kibuuka H, et al. Prospective study of acute HIV-1 infection in adults in East Africa and Thailand. N Engl J Med 2016;374:2120-30. doi: 10.1056/NEJMoa1508952 
[18] Park JH, Wook J, Sang-Woo K, et al. The clinical manifestations and chest computed tomography findings of coronavirus disease 2019 (COVID-19) patients in China: A proportion meta-analysis. Clin Exp Otorhinolaryngol 2020;13:95-105. doi: 10.21053/ceo.2020.00570

[19] Galván Casas C, Català A, Carretero Hernández G, et al. Classification of the cutaneous manifestations of COVID-19: a rapid prospective nationwide consensus study in Spain with 375 cases. Br J Dermatol 2020;183:71-7. doi: 10.1111/ bjd.19163

[20] Bouaziz JD, Duong T, Jachiet M, et al. Vascular skin symptoms in COVID-19: a French observational study [published online ahead of print, 2020 Apr 27]. J Eur Acad Dermatol Venereol 2020;34:e451-e452. doi: 10.1111/jdv.16544 